\title{
A review of modern materials used in military camouflage within the radar frequency range
}

\author{
Bogustawa Szczodrowska \\ szczodrowska@witi.wroc.pl | 익. htp://orcid.org/0000-0001-5480-8046 \\ Robert Mazurczuk \\ mazurczuk.r@witi.wroc.pl | @ http://orcid.org/0000-0001-7791-9929 \\ Military Camouflage and Reconnaissance Department, Military Institute \\ of Engineer Technology
}

Scientific Editor: Stanistaw Mtynarski, Cracow University of Technology Technical Editor: Aleksandra Urzędowska, Cracow University of Technology Press Language Editor: Tim Churcher, Big Picture Typesetting: Małgorzata Murat-Drożyńska, Cracow University of Technology Press

Received: January 7, 2021

Accepted: February 10, 2021

Copyright: @ 2021 Szczodrowska, Mazurczuk. This is an open access article distributed under the terms of the Creative Commons Attribution License, which permits unrestricted use, distribution, and reproduction in any medium, provided the original author and source are credited.

Data Availability Statement: All relevant data are within the paper and its Supporting Information files.

Competing interests: The authors have declared that no competing interests exist.

Citation: Szczodrowska, B., Mazurczuk, R. (2021). A review of modern materials used in military camouflage within the radar frequency range. Technical. Technical Transactions: e2021003. https://doi.org/ 10.37705/TechTrans/e2021003

\begin{abstract}
The article presents an overview of materials which can be employed used to camouflage objects on the modern battlefield in the radar frequency range.
\end{abstract}

Keywords: camouflage, radar range, radar wave absorbers, metamaterials 


\section{Introduction}

One of the most vital aspects of conducting combat operations has always been the survival and protection of troops on the battlefield. The significance of this particular area is constantly growing, regardless of whether the conflicts are conventional or asymmetric in nature. This increases in significance when stabilisation (or so-called low-intensity peacekeeping) missions are being lead.

One of the most effective ways to increase the protection and survival of troops is camouflage, according to the principle of "the undetected survive" or "being perceived means being hit". Due to the rapid development of reconnaissance measures enabling troops to operate in a wide spectrum of electromagnetic radiation, ranging from ultraviolet (UV)-, visible (VIS)-, near-infrared (SWIR)-, thermal (MWIR, LWIR)-, radar- (RADAR), to mechanical (ACOUSTIC, SEISMIC) waves, it is becoming increasingly necessary to continually increase the effectiveness of various means of camouflage. This poses a huge challenge, both in terms of the properties of the materials used, and design optimisation for modern and future camouflage systems.

An overview of novel materials in conjunction with a study of the feasibility of their implementation for individual applications with regard to camouflage technology on a national level in the field of radiolocation would outline the potential of this technology in Poland, in comparison with its application all over the world. This would be the next step towards developing world-class solutions. Furthermore, the results obtained following the said study should also become one of the vital elements impacting the guidelines on the future of camouflage means within the armed forces, and these findings could be the impetus for prompting new, advanced research and development projects in the field of military camouflage.

The most important advantage of the study (review) will be the possibility of using its results when developing camouflage systems in the field of radiolocation. This should directly translate into increased survivability of both the soldiers and materiel con the battlefield.

\section{Review of materials and design solutions to be applied in camouflage technology in radar frequency range}

The radar range allows military reconnaissance to be conducted at a relatively widest range (relative to optical- or thermal reconnaissance), that is of several dozen or even several hundred kilometres. This is of particular use in such situations which the background is homogeneous, i.e. the surveillance of planes or ships. As a rule, this is active sensing consisting of the transmitting element of the radar emitting a radiation beam using an emitter. When such beams encounter an object, they are reflected by the object and returned to the radar. The radar receiver receives the reflected radiation, which is subjected to time analysis (to determine the distance to the detected object) and amplitude-phase analysis (to determine the type of object detected). This mode of operation of radar devices means that the only effective countermeasure is to minimise reflected radiation, resulting in either a lack of detection or, should detection occur, incorrect identification of the object. It is generally accepted that radars operate in the range of electromagnetic radiation, mostly in the centimetre and millimetre wave spectrum. Considering currently used radars, it can be clarified that battlefield radar and tracking radars work in different wavelengths, from 1 to $20 \mathrm{GHz}, 35 \mathrm{GHz}$ and $94 \mathrm{GHz}$.

Therefore, camouflage in the radar range should be focused on at least two aspects:

- reducing the radar cross section (RCS) of objects so that a minimal proportion of the radiation emitted by the radar returns to it as a the result of being reflected from the object; 
- deformation/blurring of the radar signature of the object camouflaged to eliminate or change the details of the radar signature which allow recognition/identification of the object.

When developing comprehensive camouflage systems for objects that may find themselves on the modern battlefield, we no longer often have the opportunity to intervene at their design stage, but given the need to increase their survivability, we can accomplish the goal by using screens, thus causing signature deformation.

For the construction of camouflage systems, it is advisable to use materials with the lowest possible reflectivity, i.e. plastics, glass fibre, carbon fibre and composites.

Another group of materials consists of microwave absorbers. Several types of absorbers can be distinguished, for which the differences chiefly lie in the way they operate. The first group includes impedance-matched absorbers. In order for the electromagnetic wave to not be reflected at the interface between two different media, these media should exhibit the same impedance, which for free space equals $377 \mathrm{~W}$. Therefore, impedance-matched absorbers are pyramidal or cone-shaped, where the tops are directed in the direction of the incident wave. The size of individual pyramids or cones (their height) and the spaces between them determine the frequency range of the radiation attenuated. The drawback of these absorbers is their size (in the order of up to a dozen or so centimetres) and their fragility. However, they are very effective both in terms of their attenuation level and the range of attenuated frequencies. Another concept for these types of absorbers involves using layers of materials with low and high attenuation coefficients. Gradually increasing the percentage of material with a high attenuation coefficient in subsequent layers allows the designer to obtain an effect similar to that of pyramid structures. The advantage of such a solution is decreased thickness, while the disadvantage is a lower efficiency with regard to attenuation and frequency range. In order to obtain absorbers of an even smaller thickness, another concept was used, namely using only two layers of different impedances (the matching- and absorbing layers) but selected in such a way that the impedance of the matching layer is the sum of the impedances of the free space and that of the absorbing layer. This adjustment is only possible if the thickness of the matching layer is one quarter of the wavelength which would propagate within it. Such a solution can only be used to attenuate individual frequencies. Narrow-band absorbers can be obtained using this method.

The next group of absorbers are so-called resonant absorbers, also known as tuned- or quarter-wave absorbers. In this group of materials, for this these types of absorbers there is no impedance matching and additionally, the material is very thin, which results in only a part of the energy being absorbed. The principle of operation for this type of absorber is based on the use of the phenomenon of phase-reversal interference. A typical resonant absorber consists of an absorbing layer (with a thickness equal to one quarter of the wavelength of the radiation to be absorbed) with a metal backing. At the boundary of the free space and the absorbing layer, a partial reflection of the incident radiation occurs, and it is partly transmitted to the reflector where, as a result of this reflection, its phase shift occurs. The reflected phase-shifted wave interferes with the incident wave, resulting in its attenuation (if their amplitude is the same, they cancel each other out). The most commonly known resonant absorbers include Dallenbach layers, Salisbury screens (where instead of an absorbing layer, an air gap is used between the resistive sheet and a metal backing), and a multiplied version of Salisbury screens, also known as Jauman layers. Their special feature lies in the possibility of the broadband absorption of radiation using several layers (in the case of Dallenbach layers), the mechanical displacement of the resistive sheet (in the case of Salisbury screens), and the use of several resistive sheets, when Jauman layers are concerned. Dallenbach layers are based on ferrite materials and rubber, silicone and titanium dioxide or carbon dioxide. Resistive sheets are usually made on the basis of graphite or and carbon powders, with polyvinyl being used 
as the binder and polyethylene foam as the spacer, whereas absorbers which absorb the magnetic component are carbonyl iron- and hexaferrite-based. Their resonant frequency is a function of the size of the particles used. One of the most commonly used materials in microwave absorbers is carbon in its various forms. Originally, it was carbon black impregnated neoprene, then carbon fibres and graphite (including graphene-coated microspheres). Broadband absorbers, in turn, contain metal particles, such as: aluminium, metal-coated dielectric microspheres in the shape of flattened or elongated spheroids dispersed in matrices, iron oxides, carbonyl iron, powdered iron, powdered aluminium and copper, steel wool, nickel chromium alloys and metal wires.

Conducting polymers, which are sometimes called synthetic metals due to their good electrical conductivity, are another very promising group of materials used as microwave absorbers. What is convenient in their case is the ease with which they can be modified by oxidation/doping to obtain the desired properties. This group primarily includes polypyrroles in the form of polymer composites (polymer blends), a latex composite, or a composite with textile materials, such as polyester or cotton.

An example of a specific use of the composite is polypyrrole-coated textile marketed by Milliken \& Company under the trademark Contex ${ }^{\circ}$, which is used as a grid to attenuate microwave radiation. Another promising conductive polymer is polyaniline. This has already being studied as an element for coating textiles, including a coating for glass fibre and PET textiles. Conductive polymers can also be in the form of tubes and fibres. These are mostly employed in resonant absorbers, and especially in the Salisbury-screen version. A wide range of microwave absorbers is offered by the Laird Technologies Company and Hitek Electronic Materials Ltd. High hopes were also associated with chiral materials; however, theoretical and experimental works carried out indicates that expectations regarding this direction will not be met.

The next step includes frequency-selective surfaces (FSS). These are periodic structures with different surface textures which exhibit the ability to change the frequency of incident radiation. Incident radiation can then be transmitted, absorbed or reflected with a different level of intensity and at different frequencies, depending on the assumed structure. Among the companies offering this type of technology are SI2 Technologies Inc. and Mitsubishi.

In Poland, work to date has focused primarily on the more economically prospective civilian application market. This applies to electromagnetic compatibility issues, including shielding of devices and cables or the construction of electromagnetically sealed chambers. The only works intended for military purposes are those of the Military Institute of Engineer Technology and the Textile Research Institute in close cooperation with industry representatives, such as the Korsze, Elana, POCH, Miranda and Lubawa companies.

\section{Initial attenuation tests of the obtained samples in radar frequency range}

As part of the review of the available materials which could potentially be used in camouflage systems in the radar range, tests of samples were carried out.

In the course of the tests, the ability of materials by Emcco company to attenuate radar waves was tested, including nanomaterials and paraffin wax materials.

A PR-17 reflectometer operating in a similar manner as a low-power radar using a frequency range of $4-18 \mathrm{GHz}$ was used for the tests. The tests were carried out for three sample positions (located directly on the reference reflecting plate, $2 \mathrm{~cm}$ from the plate and $4 \mathrm{~cm}$ from the plate).

The resulting plots of attenuation obtained for the tested materials are presented in Figs. 1-6. 
Fig. 1. Plots of microwave radiation attenuation of Emcco-1 material (own elaboratory)

Fig. 2. Plots of microwave radiation attenuation of Emcco-2 material (own elaboratory)

Fig. 3. Plots of microwave radiation attenuation of Emcco-3 material (own elaboratory)

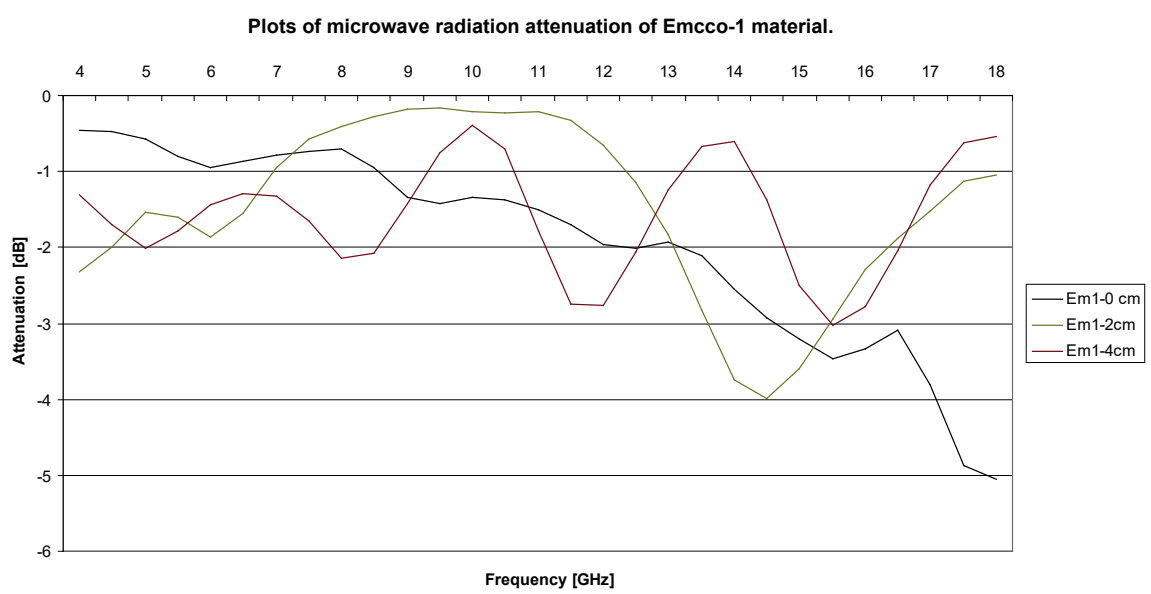

Plots of microwave radiation attenuation of Emcco-2 material.

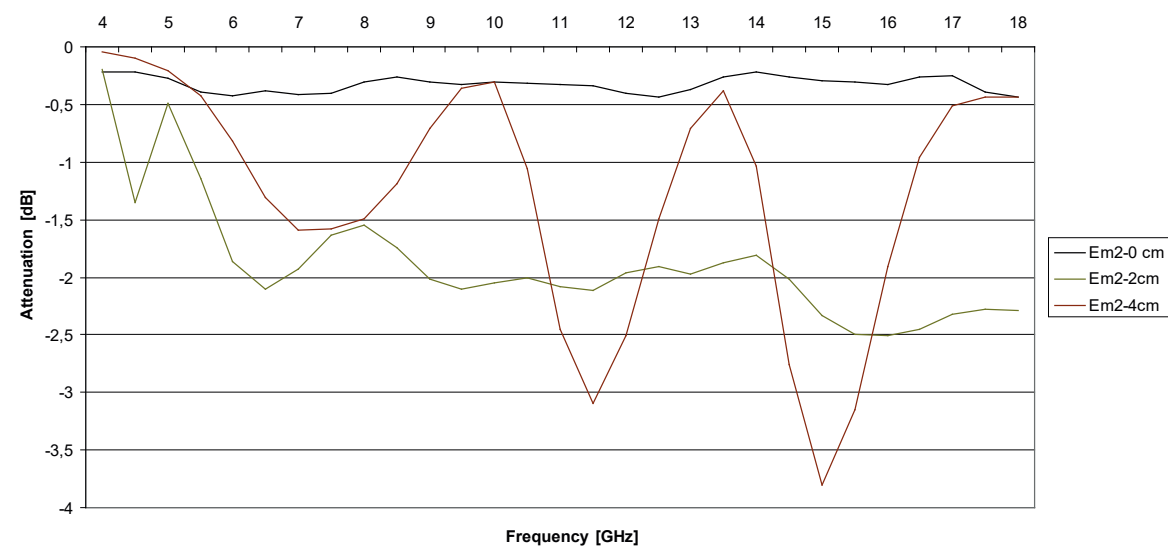

Plots of microwave radiation attenuation of Emcco-3 material.

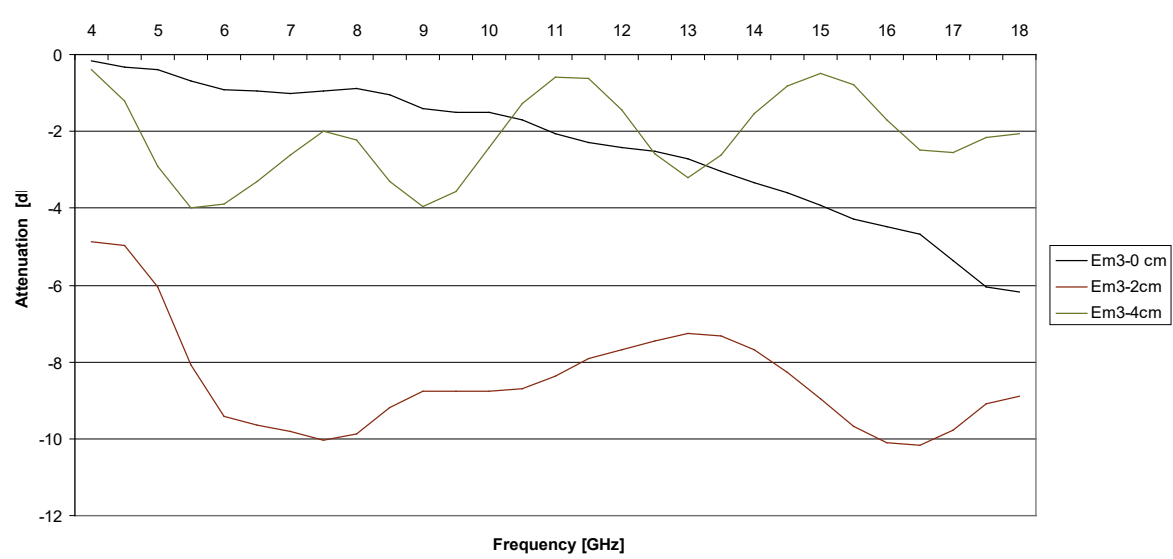


Plots of microwave radiation attenuation of Emcco-4 material.

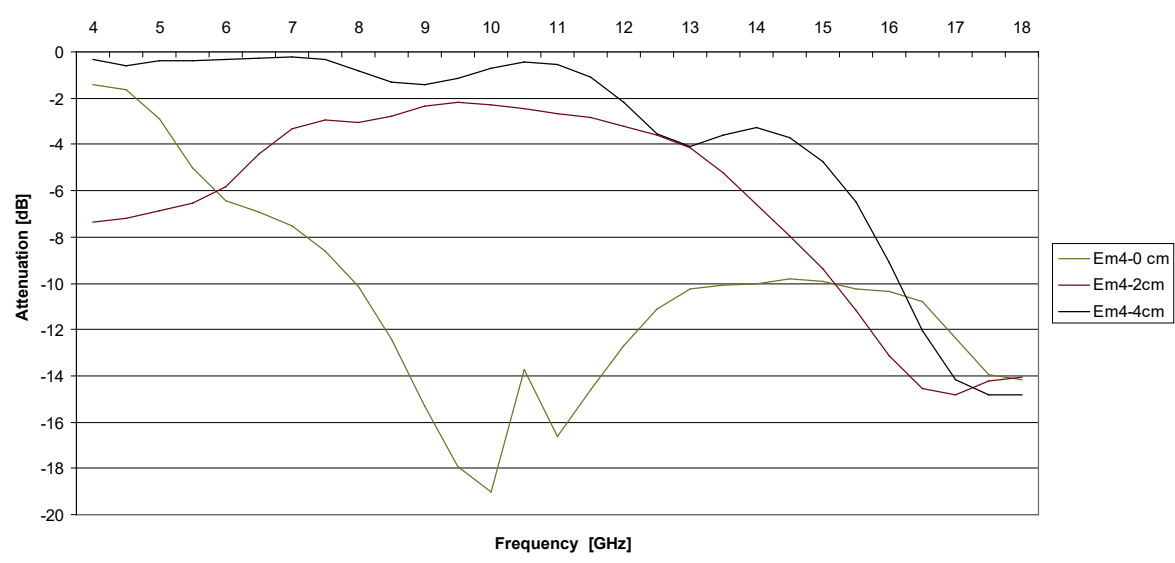

Plots of microwave radiation attenuation of paraffin material 32

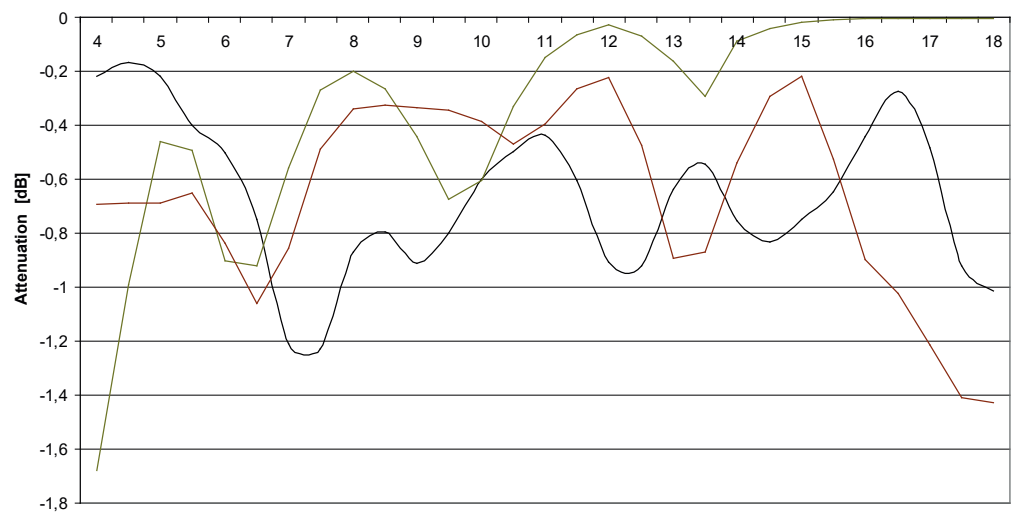

Frequency [GHz]

Plots of microwave radiation attenuation of paraffin material 41

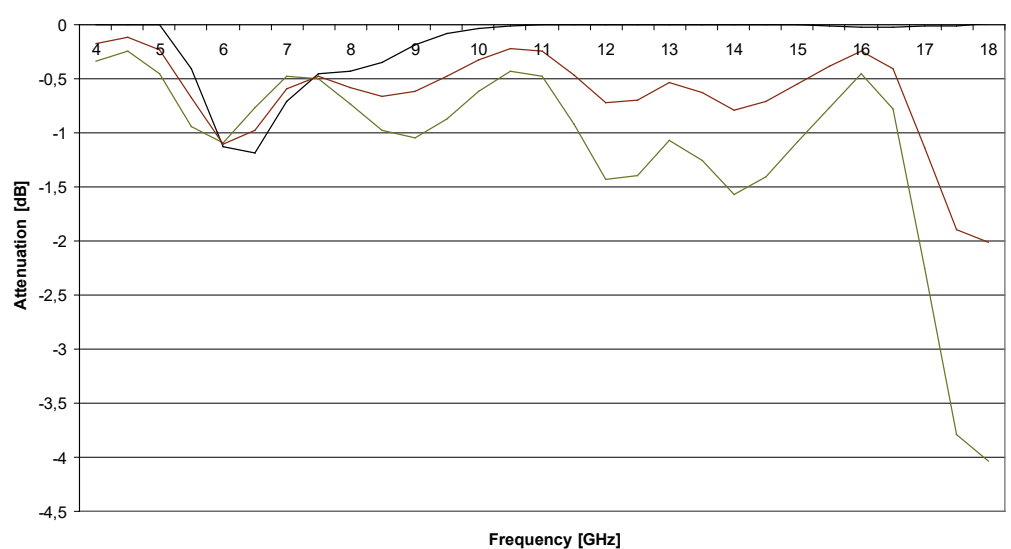

Fig. 4. Plots of microwave radiation attenuation of Emcco-4 material (own elaboratory)

Fig. 5. Plots of microwave radiation attenuation of paraffin material 32 (own elaboratory)

Fig. 6. Plots of microwave radiation attenuation of paraffin composite material 41 (own elaboratory) 
Based on the obtained measurement results (Figs. 1-6), it was found that paraffin wax containing materials are not good absorbers of microwave radiation. Selective attenuation at the level of several decibels for selected frequencies disqualifies this technical solution for camouflage applications as far as radar radiation is concerned. Emcco materials also did not live up to expectations only a variant of sample No. 4 configuration could be adopted as an element responsible for camouflage in the microwave range (attenuation at the level of $6-18 \mathrm{~dB}$ in the frequency range $6-18 \mathrm{GHz}$ ).

The verification of the samples of materials which could potentially be used in radar-range camouflage clearly indicates that the materials available for civilian use are possibly only the starting point for the development of solutions for military applications. Another issue is the consideration of the required strength parameters and resistance to environmental (climatic and mechanical) factors, the fulfilment of which often disqualifies a given solution. However, this aspect has not been tested as part of the research - the focus was only on verification of the effectiveness of camouflage.

\section{Conclusions}

Among prospective materials and technologies that could increase the efficiency of next-generation means of camouflage in the radar range are absorbers based on conductive polymers (polypyrroles, polyaniline), metal-doped microspheres, modified carbon nanotubes, selective frequency surfaces, metamaterials and tuned absorbers.

Meeting the requirements of the future battlefield by a camouflage system is conditioned on further developments in materials science, especially in the field of nanotechnology. Theoretical studies suggest that nanomaterials should be the "gold" standard, and metamaterials in particular. However, the available nanomaterial samples which had been tested confirm that further work is needed in order to increase their efficiency (Emcco materials). 


\section{References}

A New Dawn for Signature Management (2008). Military Technology, pp. 39-40. Camouflage on the Modern Battlefield (2009). Military Technology, 7, pp. 71-72. European Patent Specification EP1 033550 B1 Camouflage Material.

Folgueras, L.C., Alves, M.A., Rezende, M.C. (2010). Microwave absorbing paints and sheets based on carbonyl iron and polyaniline: measurements and simulation of their properties. Journal of Aerospace Technology and Management, Vol. 2, Jan-Apr, pp.63-70.

Guo Qing Luo, Wei Hong, Zhang-Cheng Hao, Bing Liu, Wei Dong Li, Ji Xin Chen, Hou Xing Zhou, Ke Wu (2005). Theory and Experiment of Novel Frequency Selective Surface Based on Substrate Integrated Waveguide Technology. In IEEE Transactions on Antennas and Propagation, Vol. 53 No. 12.

Lavers, Ch. (2008). Stealth Warship Design. Military Technology, 5.

MCKee, K.W., Tack D.W. (2009). Active Camouflage Technologies Come of Age. Military Technology, 7, pp. 64-70.

Messaoudi, I.(2011). More Than Just Camouflage. Military Technology, 8.

Raport z realizacji zadania badawczego, w ramach programu badawczego „Wykorzystanie nanotechnologii w nowoczesnych materiatach”(nr projektu POIG 01.01.02-02-002/08), finansowanego ze środków UE w ramach Programu Operacyjnego Innowacyjna Gospodarka, pt.: „Zastosowanie materiatów w skali nanometrycznej w procesie wytwarzania powtok funkcjonalnych na powierzchnie elastyczne o zadanych wtaściwościach grzewczych oraz ekranujących". (2012). Wroctaw: WITI, Dynamax.

Saville, P., (2005). Review of Radar Absorbing Material. Technical Memorandum $D R D C$, pp. 1-63.

Szanecki, J. (ed.) (2006). Teledetekcja. Pozyskiwanie danych. Warszawa: WNT.

US Patent No 7,511,653 B2 Radar wave camouflage structure and method of fabricating the same. 


\section{Przegląd nowoczesnych materiałów do zastosowania w maskowaniu w zakresie radiolokacyjnym}

\section{Streszczenie}

W artykule przedstawiono przegląd materiałów możliwych do zastosowania w maskowaniu w zakresie radiolokacyjnym obiektów współczesnego pola walki.

Stowa kluczowe: maskowanie, zakres radiolokacyjny, absorbery fal radarowych, metamateriały 